\title{
Azo dye removal via surfactant-assisted polyvinylidene fluoride membrane
}

\author{
Fatemeh Darbandi $^{1(\mathbb{1}}$, Azadeh Mousavi $^{1}{ }^{\mathbb{D}}$, Tayebe Bagheri Lotfabad $^{2^{+}}{ }^{\mathbb{D}}$, Amir Heydarinasab $^{1}{ }^{\mathbb{D}}$, Soheila \\ Yaghmaei $^{3}$ \\ ${ }^{1}$ Department of Chemical Engineering, Science and Research Branch, Islamic Azad University, Tehran, Iran \\ ${ }^{2}$ Department of Industrial and Environmental Biotechnology, National Institute of Genetic Engineering and Biotechnology (NIGEB), \\ Tehran, Iran \\ ${ }^{3}$ Department of Chemical and Petroleum Engineering, Sharif University of Technology, Tehran, Iran
}

\begin{abstract}
Background: Recently, concerns have been raised regarding the environmental and public health safety of azo dyes, the most widely used synthetic dyes. The membrane technique has been introduced as one of the efficient methods for dye removal treatments. Polyvinylidene fluoride (PVDF) membrane manipulated by surfactants was studied for removal of the azo dye, carmoisine.

Methods: PVDF membrane was prepared via non-solvent-induced phase separation (NIPS) and used to remove the azo dye, carmoisine. Three nonionic surfactants including Tween 20, Tween 60, and Tween 80 were used individually as additives in casting solutions to improve PVDF membrane properties.

Results: Fourier-transform infrared spectroscopy (FTIR) demonstrated the presence of functional groups of carbonyl $(\mathrm{C}=\mathrm{O})$ and hydroxyl $(\mathrm{OH})$, assigned to Tween molecules, in the membrane chemical structure. All Tween species caused a decrease in the surface hydrophobicity of PVDF membranes illustrated by the reduced contact angles. Each Tween at a $2 \%$ concentration in the dope solution led to an increase in the pore-size of PVDF membranes, which was estimated by scanning electron microscopy (SEM). However, this impact was reversed at Tween concentrations of $4 \%$. Membranes were assessed for dye removal efficiency and permeate flux in a cross-flow system. Permeability of PVDF membranes improved ( 78\%) with adding Tween 80 at a concentration of $2 \%$. Tween 60 at a $2 \%$ concentration resulted in a $\sim 45 \%$ increase in dye removal efficiency of PVDF membranes. And, atomic force microscopy (AFM) showed that Tween 60 increased membrane surface roughness.

Conclusion: Surfactant-mediated changes in the surface properties of PVDF membrane improved dye removal efficacy.

Keywords: Polyvinylidene fluoride, Coloring agents, Azo compounds, Surface-active agents

Citation: Darbandi F, Mousavi A, Bagheri Lotfabad T, Heydarinasab A, Soheila Yaghmaei S. Azo dye removal via surfactant-assisted polyvinylidene fluoride membrane. Environmental Health Engineering and Management Journal 2021; 8(1): 25-32. doi: 10.34172/EHEM.2021.04.
\end{abstract}

\section{Introduction}

Among numerous environmental issues, wastewater treatment has been one of the primary environmental concerns of the last century. Improper treatment of wastewater from industries and residential areas before disposal can pose serious environmental and public health hazards for the surrounding communities. Dye-containing sewage from various industries, including textile, paper, food, cosmetics, tannery, and pharmaceutical manufacturing, due to both its large volume and toxic composition, has been the focus of much research (1). The most widely used synthetic dyes are azo dyes, which due to their xenobiotic potential, have been the subject of many studies concerning their removal from wastewater (2-4).
Membrane technology is one of the well-known approaches used in wastewater treatment (5) and has been previously suggested for the removal of dye from effluents of textile industries (6-9). Membranes with excellent stability, flux, and separation performance are of great importance in wastewater treatment. Polyvinylidene fluoride (PVDF) is a commonly used fluoropolymer providing superior mechanical and thermal properties, which makes it an appealing choice for membrane fabrication (10). However, the hydrophobic nature of PVDF decreases water wettability of the membrane surface leading to the reduction of water permeation flux (9). Surface modifications through grafting, coating, and/or blending with additives can improve the hydrophilicity of membranes (10). Moreover, complex 
and time-consuming processes are required for grafting. More importantly, pore blocking of the membrane surface caused by coating or grafting typically reduces water permeation flux (11). However, in contrast to the aforementioned techniques, blending has been appeared as an easy and promising approach for the improvement of hydrophilic characteristics (12).

Previous studies have shown that the performance and morphology of membranes improved when pore-forming additives were used during the fabrication via the nonsolvent-induced phase separation (NIPS) method (13). Introducing an additive into the casting solution is a controlling approach in the membrane formation process (14) since the thermodynamic and kinetic responses of the casting solution are regulated by additives during the solidification process (15). Oligomeric/macromolecular materials such as PVP (polyvinyl pyrrolidone) (16) and PEG (polyethylene glycol) (17), and surfactants such as Tween 80 (18), Tween 20 (13), and Brij-58 (11) are pore-forming additives used in the preparation of PVDF membranes. Due to the hydrophilic nature of PVP and PEG polymers, they are expected to act as modifying agents in the membrane formation step, but instead, leak out from the matrix during this step resulting in the formation of pores in the membrane structure (12). Surfactants introduced into casing solution can be quickly dissolved in the dope solution due to their amphiphilic nature. Once the polymer film is immersed in the coagulant bath, the hydrophilic heads of surfactants tend to position out of the bath content. This phenomenon results in the formation of pores in the membrane (13).

In the present study, nonionic surfactants including Tween 20, Tween 60, and Tween 80 were introduced into the casting solution used for the fabrication of PVDF membrane at two concentrations of $2 \%$ and $4 \%$. The chemical and functional groups of membranes were studied using Fourier transform infrared spectroscopy (FTIR). The characteristics of membranes surface including distribution of pore sizes and hydrophilicity were compared using scanning electron microscopy (SEM) and contact angle. A crossflow system was established to evaluate the water permeability and dye removal efficiencies of membranes. Atomic force microscopy (AFM) was employed to investigate the topography and roughness of the membranes surface, which were efficient in dye removal compared to PVDF membranes.

\section{Materials and Methods \\ Chemicals}

All chemicals and reagents were of analytical grade and prepared by Merck Company, Germany. Kynar 761 PVDF powder (Arkema Inc., France) was used for the membrane preparation. Azo dye carmoisine was of commercial grade and was donated by Vista Zar Company (http://www. vistazar.com/), which imports IDACOL colors from ROHA Company.

\section{Membrane preparation}

PVDF membranes containing various percent compositions, shown in Table 1, were fabricated using a non-solvent induced phase separation (NIPS) method, which is a slightly modified approach to the method described by Nikooe and Saljoughi (11). For this purpose, PVDF was gradually added to dimethylacetamide in a 250-mL Duran bottle over a period of 1 hour, and stirred $(450 \mathrm{rpm})$ at ambient temperature. When the PVDF was completely dissolved at a concentration of $12 \%$, Tween was added piecemeal over a period of 1 hour while being stirred at $450 \mathrm{rpm}$ to reach the desired concentration. Then, stirring was continued for another 8 hours and the solution was subsequently allowed to be degassed for 24 hours. The casting solution was spread on a glass plate using a film applicator with a thickness of $5 \mu \mathrm{m}$, then, instantly immersed into the coagulation bath containing tap water at $25^{\circ} \mathrm{C}$ for $\sim 2$ minutes until completion of the phase inversion process. Finally, membranes were submerged in distilled water for 24 hours to remove entrapped solvents, and then, air-dried.

\section{Membrane properties}

Membranes were analyzed in terms of chemical groups, morphology, and hydrophilicity. The functional groups of manufactured membrane were identified by Thermo Nicolet NEXUS 870 FT-IR. The IR spectra were recorded on a wavenumber range of $300-4500 \mathrm{~cm}^{-1}$. The membranes surface morphologies were investigated using SEM (AIS2300C, Korea) at $20 \mathrm{kV}$ where samples were gold coated. Moreover, the diameters of at least 20 pores were estimated for each membrane using ImageJ software 1.52p through the SEM images. The means were subsequently graphed with error bars using Microsoft Excel.

Hydrophilicity of each membrane was determined using measurements of contact angle between a deionized water droplet and membrane surface using a Drop Shape Analyzer (Krüss DSA25E, Germany). The contact angles were measured at five sites of each membrane. The averages were calculated and plotted with error bars using Microsoft Excel.

\section{Membrane performance}

The prepared membranes were evaluated for their

Table 1. Mass percent composition for casting solutions

\begin{tabular}{lccc}
\hline Membranes & $\begin{array}{c}\text { PVDF } \\
\text { (wt. \%) }\end{array}$ & $\begin{array}{c}\text { Tween } \\
\text { (wt. \%) }\end{array}$ & $\begin{array}{c}\text { Solvent } \\
\text { (wt. \%) }\end{array}$ \\
\hline PVDF & 12 & 0 & 88 \\
\hline PVDF-T20-2\% & 12 & 2 & 86 \\
\hline PVDF-T20-4\% & 12 & 4 & 84 \\
\hline PVDF-T60-2\% & 12 & 2 & 86 \\
\hline PVDF-T60-4\% & 12 & 4 & 84 \\
\hline PVDF-T80-2\% & 12 & 2 & 86 \\
\hline PVDF-T80-4\% & 12 & 4 & 84 \\
\hline
\end{tabular}


performance in a cross-flow system. Figure 1 shows the schematic diagram of experimental set-up including a reservoir, pump, valves, pressure gauges, and membrane cell. All experiments were conducted at room temperature $\left(25 \pm 2^{\circ} \mathrm{C}\right)$. Membranes with an effective surface area of $44.1 \mathrm{~cm}^{2}$ were compacted in cell (Figure $2 \mathrm{~b}$ ). The synthetic dye solution was fed into the cell from the feed tank at a pressure of 1 bar. The retentate was returned to the tank and permeate was collected at specified time intervals. Permeate volume was measured and dye concentration was determined in the permeate using the spectrophotometric method as described by Kiayi et al (19). Samples were scanned between $200 \mathrm{~nm}$ to $800 \mathrm{~nm}$ via the UV-vis spectrophotometer (HACH, DR5000 ${ }^{\mathrm{TM}}$, Germany). The absorbance was recorded at $\lambda_{\max }$ of carmoisine (515 $\mathrm{nm}$ ) for each sample and converted to a corresponding concentration via standard curve. Finally, dye rejection was calculated using Eq. (1). Experiments were performed in triplicate and repeated in three subsequent trials. The means were plotted with error bars using Microsoft Excel.

$R \%=\left[\frac{C_{f}-C_{p}}{C_{f}}\right] \times 100$

where, $C_{f}$ and $C_{p}$ are dye concentrations in feed and permeate $(\mathrm{mg} / \mathrm{L})$, respectively. Moreover, permeate flux $\left(J_{\text {per }}\right)$ was estimated via Eq. (2) using the permeate volume $\left(V_{p e r}\right)$ measured every 5 minutes $(\Delta t)$ during the experiment.

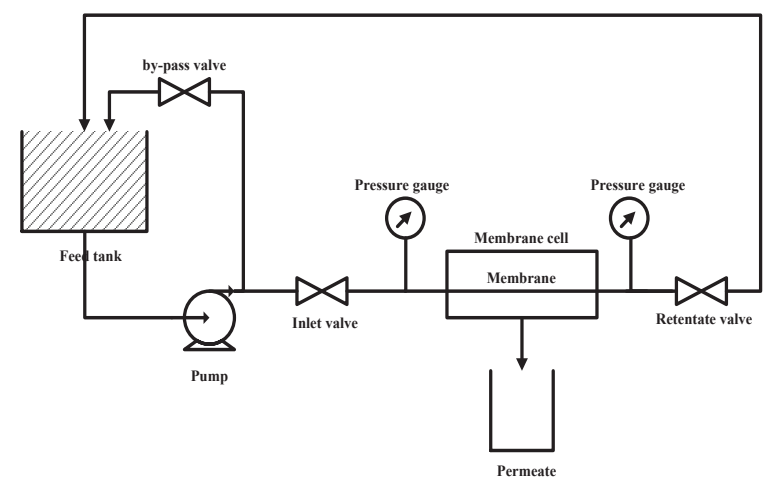

Figure 1. Schematic diagram of cross-flow system to evaluate membrane performance for water permeation flux and dye rejection.

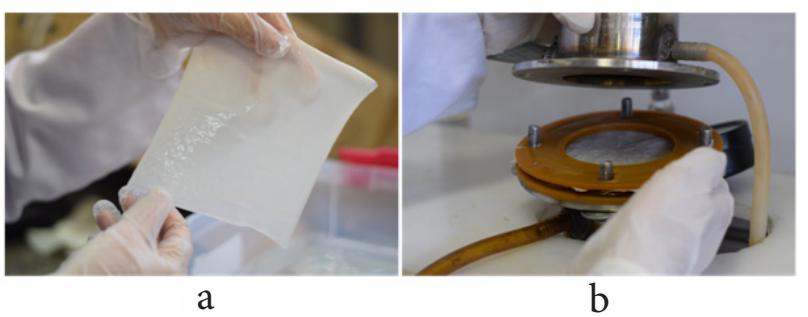

Figure 2. Display of PVDF membrane (a) immediately after immersion in distilled water and, (b) air-dried and compacted in cross-flow cell.
$J_{p e r}=\frac{V_{p e r}}{\Delta t \times A}$

\section{Atomic force microscopy}

The roughness and surface morphology of PVDF membrane were compared with those fabricated using Tween 60 (2\%) additive. Membranes were analyzed via $\mathrm{AFM}$ by a DualScope ${ }^{\mathrm{TM}}$ scanning probe-optical microscope (DME model C-21, Denmark). Images of the membrane surfaces were made using a scan size of $50 \times$ $50 \mu \mathrm{m}$. AFM images were analyzed using DualScope ${ }^{\mathrm{Tm}} /$ Rasterscope $^{\text {Tw }}$ SPM software (version 2.1.1.2) to obtain the average roughness $(\mathrm{Ra})$ of membrane surface and the root mean square (RMS).

\section{Statistical analysis}

Data were analyzed using statistics such as the mean, standard deviation, and coefficients of variation by Microsoft Excel. The graphs represent error bars with a plus/minus one standard deviation from the mean.

\section{Results}

\section{Membranes structure and properties}

The membranes were prepared in $10 \times 10 \mathrm{~cm}$ dimensions as shown in Figure 2a. The main physicochemical properties of the membranes were determined using the FTIR and SEM studies as well as contact angle measurements.

\section{Fourier-transform infrared spectroscopy}

The Fourier-transform infrared spectroscopy (FTIR) spectra for the fabricated membranes are shown in Figure 3. A strong band at $\sim 1733 \mathrm{~cm}^{-1}$ in the spectrum of membranes prepared in the presence of different Tween species is attributed to the $\mathrm{C}=\mathrm{O}$ group originating from Tween components. Moreover, all Tween species have hydroxyl $(\mathrm{OH})$ groups in their structures appearing as a wide peak at $3460-3495 \mathrm{~cm}^{-1}$ in the spectrum of Tweencontaining membranes (13). These observations indicate the residual Tween in membrane structure. The peaks at $480-500, \sim 835$, and $\sim 885 \mathrm{~cm}^{-1}$ are attributed to C-F stretching. Bands at 1390-1410 and 1624-1638 $\mathrm{cm}^{-1}$ are attributed to C-C stretching and at $\sim 2920$ and $\sim 3020 \mathrm{~cm}^{-1}$, are attributed to $\mathrm{C}-\mathrm{H}$ stretching (20).

\section{Scanning electron microscopy}

Electron microscopy images in Figure 4 show that regardless of the type of Tween used, a combination of $2 \%$ Tween in dope solution leads to the formation of pores of similar diameter in the membrane structures. However, membrane pores undergo contraction at a Tween concentration of $4 \%$. This is further confirmed by comparing the pore diameters estimated from SEM images and shown in Figure 5. Moreover, the coefficients of variation ( $C V=\frac{\sigma}{\mu} \times 100$, where $\sigma$ is standard deviation and $\mu$ is mean) were estimated as $\sim 37 \%, \sim 35 \%, \sim 49 \%, \sim 48 \%$, 


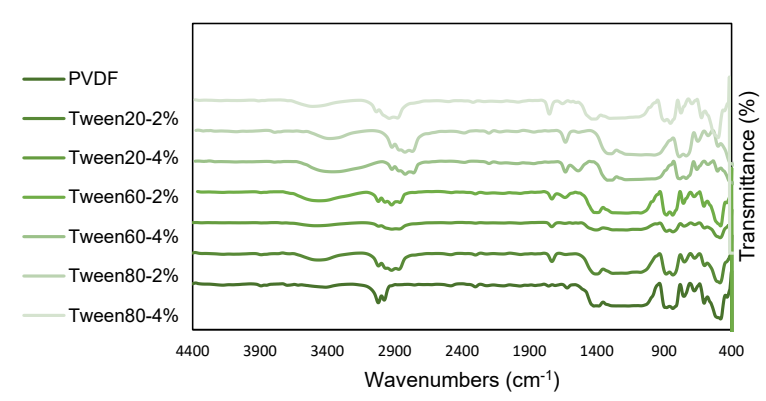

Figure 3. FTIR spectra of the PVDF membranes prepared in the absence of Tween additives as well as in the presence of Tween 20 , Tween 60 , and Tween 80 at concentrations of $2 \%$ and $4 \%$.

$\sim 51 \%, \sim 40 \%$, and $\sim 49 \%$ for membrane made from PVDF, PVDF + T20-2\%, PVDF + T20 - 4\%, PVDF + T60 - 2\%, PVDF + T60 - 4\%, PVDF + T80-2\%, and PVDF + T80 - $4 \%$, respectively. The CV is a measure of dispersion around the mean; therefore, combining Tween in the dope solution increased $\mathrm{CV}$, indicating that the uniformity of membrane pore size decreased.

\section{Contact angle measurements}

The averages of contact angle measurements for water droplets on the surface of each PVDF membrane are shown in Figure 5. The results show that combination of Tween and dope solution reduced contact angle, indicating that surface hydrophilicity increased. However, Tweens at a concentration of $4 \%$ resulted in a higher contact angle and/or lower hydrophilicity compared to a $2 \%$ concentration. This unexpected change is discussed in further details in the Discussion section.

\section{Water permeability and dye removal}

A cross-flow system was used to evaluate PVDF membranes prepared for water permeability and dye removal efficiency to assess the effect of Tween additive on the membrane fabrication. Permeates were measured for volume extent and assessed for dye concentration. Figure 5 indicates that water permeation increased from $7.07 \mathrm{~lm}^{-2} \mathrm{~h}^{-1}$ for PVDF membrane to 12.6 and $10.3 \mathrm{Lm}^{-}$ ${ }^{2} \mathrm{~h}^{-1}$ when Tween 80 was added to casting solution at concentrations of $2 \%$ and $4 \%$, respectively. These indicate $\sim 78 \%$ and $\sim 45 \%$ increases in the permeability of PVDF polymer, respectively. Tween 80 slightly improved the dye removal efficiency of PVDF as $\sim 8 \%$ and $\sim 29 \%$ when added to dope solution at concentrations of $2 \%$ and $4 \%$, respectively (shown in Figure 5). The double bond of $\mathrm{C}=\mathrm{C}$ in the hydrophobic tail of the Tween 80 structure may explain why Tween 80 exhibits lower hydrophobic tendencies and higher water flux permeation of PVDF membranes compared to its counterparts. Tween 60 at a concentration of $2 \%$ resulted in a $\sim 45 \%$ increase in dye removal (from $\sim 66 \%$ to $\sim 96 \%$ ) and only a $\sim 7.4 \%$ increase in water permeability (from $\sim 7$ to $\sim 7.6 \mathrm{Lm}^{-2} \mathrm{~h}^{-1}$ ) of the PVDF membranes.

\section{Atomic force microscopy}

The effect of combination of Tween 60 (2\%) and dope solution of PVDF on the surface roughness of the membrane was investigated via AFM. Figure 6 shows the AFM images of the top surface of the membranes. The $\mathrm{R}_{\mathrm{a}}$ and RMS roughness of these membrane surfaces were calculated from the AFM images on a $5 \times 5 \mu \mathrm{m}$ lateral area. Table 2 indicates that the $\mathrm{R}_{\mathrm{a}}$ and RMS of the membrane surface noticeably increased when Tween 60 was added to the PVDF. This implies that the addition of Tween, the introduction of its functional groups, significantly altered the membrane surface.

\section{Discussion}

PVDF is a widely used polymer to produce membranes

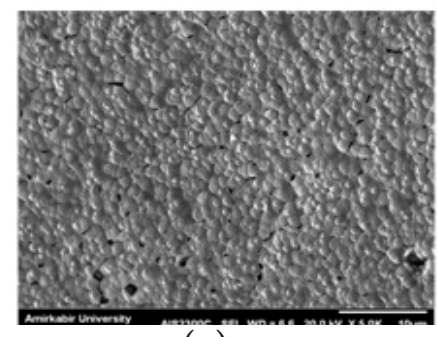

(a)

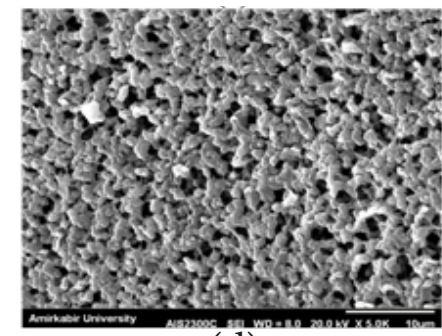

(d)

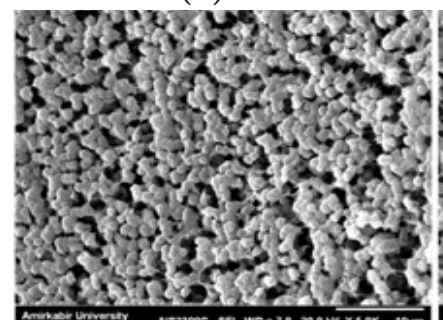

(b)

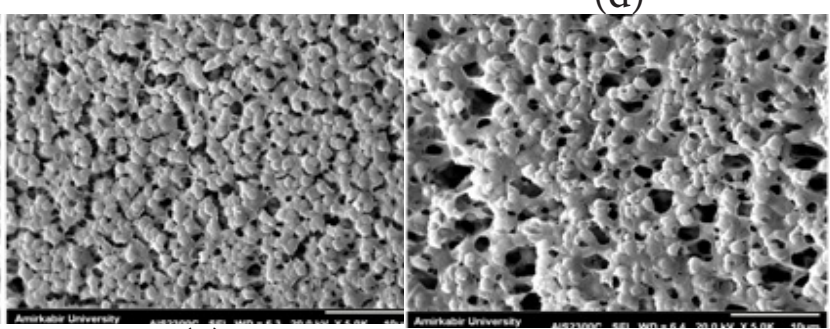

(c)

(f)

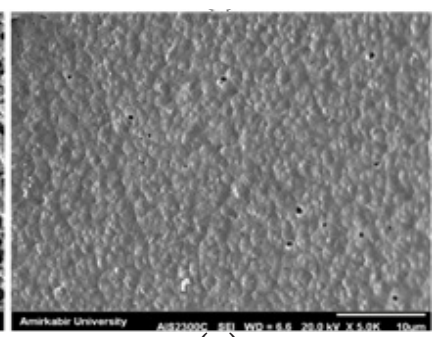

(e)

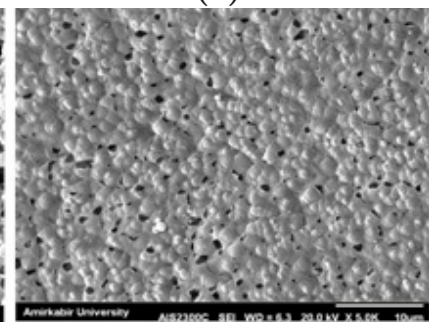

(g)

Figure 4. SEM images of the surface of PVDF membranes prepared with different concentrations of various types of Tween with magnification of 5k. (a) non-Tween, (b) Tween 20-2\%, (c) Tween 20-4\%, (d) Tween 60-2\%, (e) Tween 60-4\%, (f) Tween $80-2 \%$ and, (g) Tween $80-4 \%$. 
Table 2. Surface roughness of PVDF membrane without additives and with addition of Tween 60 at a concentration of $2 \%$

\begin{tabular}{|c|c|c|}
\hline Membranes & $\begin{array}{c}\text { Calculated } \\
\text { average roughness }\left(R_{a}\right) \\
(n m)\end{array}$ & $\begin{array}{c}\text { Calculated } \\
\text { root mean square (RMS) } \\
\text { roughness }(\mathrm{nm})\end{array}$ \\
\hline PVDF & 75.2 & 96.5 \\
\hline PVDF-T60-2\% & 108 & 131 \\
\hline
\end{tabular}

The $R_{a}$ and RMS were estimated from the AFM images over a $5 \times 5 \mu \mathrm{m}$ lateral area.

for various industrial applications. However, PVDF membranes suffer from a hydrophobic nature leading to reduced water permeation flux (9). Surface modification through pore-forming additives including surfactant molecules has been suggested as a promising method to regulate the hydrophilic manifest of PVDF membranes $(11,13,18)$. In the present study, nonionic surfactants Tween 20, Tween 60, and Tween 80 were introduced into the casting solution used for the fabrication of PVDF membrane at two concentrations of $2 \%$ and $4 \%$. FTIR studies (Figure 3) revealed that Tween was present in the fabricated membranes and was not removed during the washing steps. Previous research also reported the presence of surface modifier and pore former additives in membrane matrix when used in the fabrication of membranes. For example, sodium dodecyl sulfate (SDS), cetyltrimethylammonium bromide (CTAB), and Triton X-100 (Triton) appeared on the FTIR spectrum of the membrane when used during the fabrication of cellulose acetate membrane $(21,22)$. Also, the absorbance peaks of Pluronic and PEG macromolecules were shown in the ATR-FTIR spectra of polyethersulfone (PES) membrane when used as additives in the membrane fabrication step (23).

Electron microscopy images (Figure 4) revealed that adding 2\% Tween into dope solution led to the formation and/or increase in the membrane pore sizes due to the amphiphilic nature of Tween. Once the polymer film is immersed in the water bath, the hydrophilic moiety of Tween is oriented towards the water bulk resulting in the formation of pores in the membrane structure (13). At higher Tween concentrations (4\%), membrane pore size decreased. This may be due to the fact that higher concentrations of Tween create a more viscous casting solution preventing hydrophilic heads of surfactant molecules from migrating toward the water bath. Therefore, pore formation is restricted (12). Moreover, Figure 5 illustrates that adding Tween in dope solution resulted in a CV increase, indicating a decrease in the uniformity of membrane pore size. Chang et al (13), through the FESEM imaging of membranes reported that PVDF membrane had a dense skin layer and was free of pores at a resolvable length-scale of $\sim 10 \mathrm{~nm}$. However, with the addition of Tween-20 (1\%) into the dope solution, nano-pores begin to appear on the top surface. Increasing Tween 20 from 1 to $10 \%$ in dope solution increases the pore size and porosity and reduces the thickness of the skin layer. However, the bottom surfaces of the membranes were less affected by Tween 20 as the surfactant would leave this region and migrate upwards. Tween 20 also changed the bottom surfaces of the membranes from sheaf- or sphere-like to stick-like (13). Safari et al (24) examined SDS, Triton X-100 and Tween 80 as additives for the manufacture of PVDF membranes. The cross-sectional morphological structures revealed the formation of macro-voids and finger-like structures as well as a spongy layer in the presence of these surfactants. Amirilargani et al studied the effects of Tween 80 on the morphology of flat sheet PES membranes (25). SEM analysis showed that the addition of Tween 80 to the casting solution increases water content and porosity of the membrane support layer. Amirilargani et al also assessed the effect of Tween 20 on the structures of PES membranes. Using Tween 20 from $1 \%$ to $4 \%$, the membrane morphology changed slowly

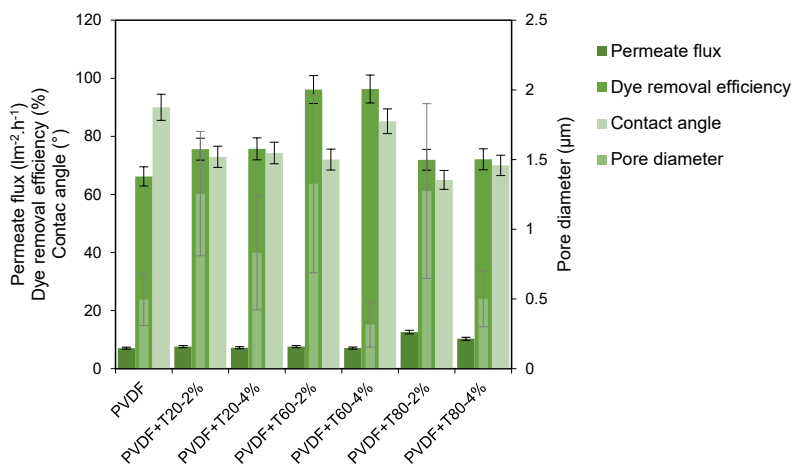

Figure 5. Pore diameter, contact angle, dye removal efficiency, and permeate flux in the absence of Tween additives and in the presence of Tween 20, Tween 60, and Tween 80 at concentrations of $2 \%$ and $4 \%$.

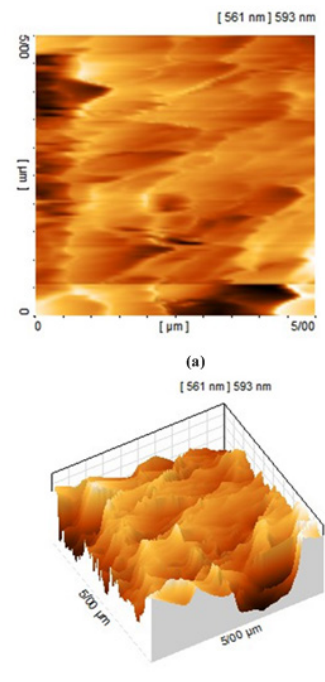

(e)
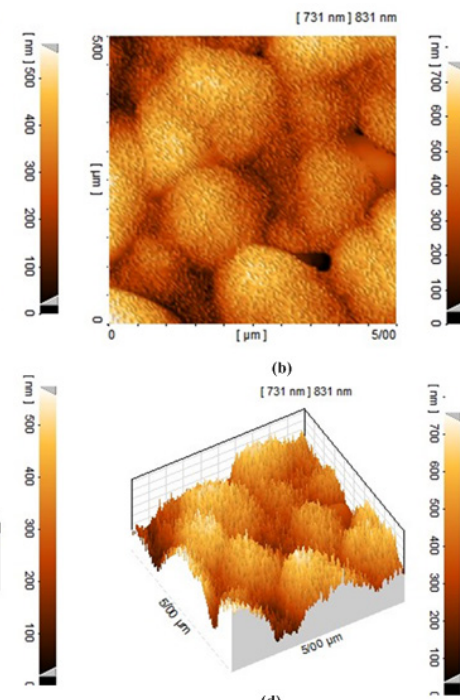

(d)
Figure 6. Surface AFM images on an area of $5 \times 5 \mu \mathrm{m}$ of PVDF membranes prepared $(a, c)$, with no Tween additives, and (b, d), prepared with the addition of Tween 60 at a concentration of $2 \%$ in casting solution. 
from a thin finger-like structure with a spongy texture to a long, wide finger-like structure with some macrovoids (26). Contact angle measurements (Figure 5) indicated that the presence of Tween in dope solution reduced contact angle, indicating an increase in the surface hydrophilicity. This is in keeping with the aforementioned hypothesis that the hydrophilic moiety of Tween forced into water bulk during the water bath immersion results in the surface hydrophilicity of membranes. In addition, the carbonyl $(\mathrm{C}=\mathrm{O})$ and hydroxyl $(\mathrm{OH})$ groups in the membrane structure originating from Tween additives may contribute to the increase in hydrophilicity of the membranes. Similar reports have been conducted on the polymeric membrane modified by nonionic surfactants. Nasrul et al (27) and Arahman et al (28) used a nonionic surfactant, Tetronic 1307, in the fabrication of PES membranes. Contact angle measurements indicated improved hydrophilicity of PES when Tetronic 1307 was used in polymer solution. This was attributed to surfactant remaining on the surface membrane as indicated by FTIR analysis. Omidvar et al used nonionic surfactant Brij 58 as a pore-former additive in the preparation of PES membrane. They reported that when Brij 58 was used at a concentration of $6 \mathrm{wt}$. \% in casting solutions, the contact angle of PES membrane reduced from $74.7^{\circ}$ to $28.3^{\circ}$ measured for pure PES membrane (29).

Also shown in Figure 5, Tweens at a concentration of $4 \%$ resulted in a higher contact angle and/or lower hydrophilicity compared to a $2 \%$ concentration. Due to the fact that surfactant-containing systems exhibit different thermodynamic behaviors below and beyond the critical micelle concentrations, they tend to form aggregate structures instead of orienting in interfacial positions (30). Similar results have been reported by Wahab et al when they used Brij35, a nonionic surfactant, to improve the performance of PVDF membranes fabricated using the NIPS method. They reported that when the Brij concentration increased from 1 wt $\%$ to 5 wt $\%$, the membrane contact angle decreased from $71^{\circ}$ to $50^{\circ}$. However, when the Brij concentration was further increased to $7 \mathrm{wt} \%$, the contact angle increased to $56^{\circ}$ (12). Brij is a commonly used nonionic surfactant with a hydrophilic-lipophilic balance number of 16.9. When the hydrophilic-lipophilic balance number is higher than 10, this is an indication of greater affinity for water (hydrophilic). Therefore, this hydrophilicity results in the segregation of the Brij added to the membrane surface during phase separation, subsequently, increasing the membrane hydrophilicity and reducing the contact angle. When the Brij concentration was further increased, the viscosity of the dope solution also increased due to an increase in the total polymer concentration, and this increase in viscosity subsequently led to a decrease in the Brij segregation rate during the phase separation. Thus, this ultimately resulted in a decrease in hydrophilicity and an increase in contact angle. Furthermore, Chang et al in their research on the combination of Tween 20 and dope solution of PVDF membrane demonstrated that contact angles were not significantly affected by increasing the Tween 20 concentration from 0 to $10 \%$. They reported average contact angles of $82^{\circ}, 83^{\circ}, 82^{\circ}, 83^{\circ}, 86^{\circ}$, and $86^{\circ}$ for Tween 20 concentrations of $0,1,3,5,7.5$, and $10 \%$, respectively, but did not elaborate on these findings (13).

Furthermore, water permeability and dye removal studies (Figure 5) showed that while the Tween concentration increased from $2 \%$ to $4 \%$, water permeation slightly reduced but dye removal efficiency was not significantly affected. The above-mentioned decrease in pore size and hydrophilicity of membranes brought about by increases in Tween from $2 \%$ to $4 \%$ could be responsible for reduced water permeability. However, the mechanism of dye rejection by PVDF membrane requires further investigation. The PVDF membrane surface is negatively charged in water in a wide $\mathrm{pH}$ range from 3 to 8 (31) and carmoisine with two sulfonate groups is negatively charged in aqueous solution (32-34). These combined negative charges of both membrane and azo dye results in higher intermolecular repulsions leading to dye rejection and removal by PVDF membrane. Moreover, the presence of Tween molecules as a nonionic surfactant on the membrane surface may create a spatial hindrance for negatively charged dye molecules leading to a synergistic increase in dye rejection. This depends on the Tween type but not concentration so that utilizing the same type of Tween, regardless of its concentration, will render similar results for dye removal. In a similar study, Tran et al demonstrated high rejections for anionic dyes, eriochrome black T (EBT, 83.5\%), and naphthol blue black (NBB, 89.1\%) using PVDF UF membrane. They have explained that both EBT and NBB prevailed in the anion state in aqueous solution, due to strongly acidic sulfonate groups $\left(-\mathrm{SO}_{3}\right)$ in their molecular structures, causing them to be repulsed away from the negatively charged PVDF membrane (35).

The dye rejection through modified PVDF by Tween 60 ( $96 \%)$ was comparable to what was reported in literature for PVDF membrane. Zeng et al recorded rejections of $78.7 \%, 76.3 \%$, and $88.8 \%$ by PVDF membrane for reactive dyes including direct red 28, direct yellow 4 , and direct blue 14, respectively (36). Tran et al reported that the PVDF membrane successfully rejected zwitterionic rhodamine $\mathrm{B}$, cationic methylene blue, anionic EBT, and anionic NBB as $1.1 \%, 45.6 \%, 83.5 \%$, and $89.1 \%$, respectively (35). Nikooe and Saljoughi added Brij-58 nonionic surfactant into the casting solution of PVDF membrane used for removal of Reactive red 141 from aqueous solution. Brij, at a concentration of $2 \%$, reduced the dye removal efficiency from $94 \%$ to $90 \%$ and increased permeate flux from 7.2 to $31.2 \mathrm{Lm}^{-2} \mathrm{~h}^{-1}$ (11). Therefore, the comparison of the results showed that Tween 60 was more effective than Brij-58 in increasing the dye removal efficiency of the PVDF membrane, but Brij demonstrated better results 
in the improvement of permeate flux.

Surface roughness of the membrane fabricated in the presence of Tween 60 (2\%) in dope solution of PVDF was investigated via AFM. Images in Figure 6 and calculated parameters ( $\mathrm{Ra}$ and $\mathrm{RMS}$ ) in Table 2, confirmed the increased roughness of membrane surface due to the addition of Tween 60 to PVDF. This increase in roughness after the addition of surfactants to the polymer membrane has also been mentioned in other investigations $(14,37,38)$. Rahimpour et al reported that membrane roughness parameters increased with the addition of surfactants in the PES casting solution. Triton X-100 as a nonionic surfactant increased roughness compared to other surfactants (SDS, CTAB) used in their study (14).

\section{Conclusion}

In this study, the effects of Tween 20, Tween 60, and Tween 80 at concentrations of $2 \%$ and $4 \%$ in polymeric PVDF membranes were examined. The addition of these surfactants improved PVDF membranes, exhibiting higher water permeability and azo dye removal efficiencies. FTIR analysis showed the presence of Tween molecules in the membrane chemical structure. SEM images indicated pore formation in the membranes due to the addition of Tween. Contact angle measurements demonstrated the reduction of hydrophobicity or increase in the wettability of PVDF membranes containing Tween additives. Investigations of membrane performance in a cross-flow system revealed that Tween 80 at a concentration of $2 \%$ exhibited the most efficiency in promoting the permeate flux, compared to its other counterparts. However, Tween 60 at a concentration of $2 \%$ showed the highest efficiency in removal of azo dye carmoisine. However, further studies are required to investigate the effects of the synchronic use of both Tween 60 and Tween 80 on the PVDF membrane in terms of surface properties and performance. The findings of the present study indicate that Tween-modified PVDF membranes have great potential for use in the treatment of dye-containing wastewaters.

\section{Acknowledgments}

The authors gratefully acknowledge the Vista Zar Company (http://www.vistazar.com/) for donating the azo dye carmoisine.

\section{Ethical issues}

Not applicable.

\section{Competing interests}

The authors declare that they have no conflict of interests.

\section{Authors' contributions}

TBL conceived and designed the research. TBL, FD, and AM conducted the experiments. AH and SY contributed to the analysis data. TBL wrote the manuscript. All authors read and approved the manuscript.

\section{References}

1. Mishra S, Maiti A. The efficacy of bacterial species to decolourise reactive azo, anthroquinone and triphenylmethane dyes from wastewater: a review. Environ Sci Pollut Res Int 2018; 25(9): 8286-314. doi: 10.1007/ s11356-018-1273-2.

2. Misal SA, Gawai KR. Azoreductase: a key player of xenobiotic metabolism. Bioresour Bioprocess 2018; 5(1): 17. doi: 10.1186/s40643-018-0206-8.

3. Omidi Khaniabadi Y, Mohammadi MJ, Shegerd M, Sadeghi S, Saeedi S, Basiri H. Removal of Congo red dye from aqueous solutions by a low-cost adsorbent: activated carbon prepared from Aloe vera leaves shell. Environ Health Eng Manag 2017; 4(1): 29-35. doi: 10.15171/ehem.2017.05.

4. Suresh S. Biosorption of acid dyes from aqueous solution using Curcuma angustifolia scales. Environ Health Eng Manag 2016; 3(3): 123-9. doi: 10.15171/ehem.2016.10.

5. Rezaei L, Dehghani M, Hassani AH, Alipour V. Seawater reverse osmosis membrane fouling causes in a full scale desalination plant; through the analysis of environmental issues: raw water quality. Environ Health Eng Manag 2020; 7(2): 119-26. doi: 10.34172/ehem.2020.14.

6. Ahmad A, Mohd-Setapar SH, Chuong CS, Khatoon A, Wani WA, Kumar R, et al. Recent advances in new generation dye removal technologies: novel search for approaches to reprocess wastewater. RSC Adv 2015; 5(39): 30801-18. doi: 10.1039/c4ra16959j.

7. Makertihartha I, Rizki Z, Zunita M, Dharmawijaya PT. Dyes removal from textile wastewater using graphene based nanofiltration. AIP Conf Proc 2017; 1840(1): 110006. doi: 10.1063/1.4982336.

8. Pavithra KG, Kumar PS, Jaikumar V, Rajan PS. Removal of colorants from wastewater: a review on sources and treatment strategies. J Ind Eng Chem 2019; 75: 1-19. doi: 10.1016/j.jiec.2019.02.011.

9. An AK, Guo J, Jeong S, Lee EJ, Alizadeh Tabataba SA, Leiknes T. High flux and antifouling properties of negatively charged membrane for dyeing wastewater treatment by membrane distillation. Water Res 2016; 103: 362-71. doi: 10.1016/j.watres.2016.07.060.

10. Huang JP, Shao YM, Liu LL, Ma CY. Comparative study on anti-fouling properties and application of two PVDF blend membranes in wastewater treatment. Adv Mat Res 2012; 550-553(3): 2164-9. doi: 10.4028/www.scientific.net/ AMR.550-553.2164.

11. Nikooe N, Saljoughi E. Preparation and characterization of novel PVDF nanofiltration membranes with hydrophilic property for filtration of dye aqueous solution. Appl Surf Sci 2017; 413: 41-9. doi: 10.1016/j.apsusc.2017.04.029.

12. Wahab MY, Muchtar S, Jeon S, Fang LF, Rajabzadeh S, Takagi R, et al. Synergistic effects of organic and inorganic additives in preparation of composite poly(vinylidene fluoride) antifouling ultrafiltration membranes. J Appl Polym Sci 2019; 136(27): 47737. doi: 10.1002/app.47737.

13. Chang HH, Chen SC, Lin DJ, Cheng LP. The effect of Tween-20 additive on the morphology and performance of PVDF membranes. J Memb Sci 2014; 466: 302-12. doi: 10.1016/j.memsci.2014.05.011.

14. Rahimpour A, Madaeni SS, Mansourpanah Y. The effect of anionic, non-ionic and cationic surfactants on morphology and performance of polyethersulfone ultrafiltration 
membranes for milk concentration. J Memb Sci 2007; 296(1-2): 110-21. doi: 10.1016/j.memsci.2007.03.029.

15. Liu H, Liao X. The effects of fluorocarbon special surfactant (FS-30) additive on the phase inversion, morphology and separation performance of poly(vinylidene fluoride) (PVDF) membranes. Sep Purif Technol 2019; 212: 619-31. doi: 10.1016/j.seppur.2018.11.060.

16. Simone S, Figoli A, Criscuoli A, Carnevale MC, Rosselli A, Drioli E. Preparation of hollow fibre membranes from PVDF/PVP blends and their application in VMD. J Memb Sci 2010; 364(1-2): 219-32. doi: 10.1016/j. memsci.2010.08.013.

17. Ngang HP, Ahmad AL, Low SC, Ooi BS. The influence of PEG additive on the morphology of PVDF ultrafiltration membranes and its antifouling properties towards proteins separation. J Teknol 2014; 70(2): 23-7. doi: 10.11113/ jt.v70.3430.

18. Zhang PY, Yang H, Xu ZL. Preparation of polyvinylidene fluoride (PVDF) membranes via nonsolvent induced phase separation process using a Tween 80 and $\mathrm{H} 2 \mathrm{O}$ mixture as an additive. Ind Eng Chem Res 2012; 51(11): 4388-96. doi: 10.1021/ie201806v.

19. Kiayi Z, Bagheri Lotfabad T, Heidarinasab A, Shahcheraghi F. Microbial degradation of azo dye carmoisine in aqueous medium using Saccharomyces cerevisiae ATCC 9763. J Hazard Mater 2019; 373: 608-19. doi: 10.1016/j. jhazmat.2019.03.111.

20. Lei H, Liu L, Huang L, Li W, Xing W. Novel anti-fouling PVDF-g-THFMA copolymer membrane fabricated via photoinduced $\mathrm{Cu}(\mathrm{II})$-mediated reversible deactivation radical polymerization. Polymer 2018; 157: 1-8. doi: 10.1016/j.polymer.2018.10.019.

21. Ghaemi N, Madaeni SS, Alizadeh A, Daraei P, Vatanpour V, Falsafi M. Fabrication of cellulose acetate/sodium dodecyl sulfate nanofiltration membrane: characterization and performance in rejection of pesticides. Desalination 2012; 290: 99-106. doi: 10.1016/j.desal.2012.01.013.

22. Ghaemi N, Madaeni SS, Alizadeh A, Daraei P, Zinatizadeh AA, Rahimpour F. Separation of nitrophenols using cellulose acetate nanofiltration membrane: influence of surfactant additives. Sep Purif Technol 2012; 85: 147-56. doi: 10.1016/j.seppur.2011.10.003.

23. Loh CH, Wang R, Shi L, Fane AG. Fabrication of high performance polyethersulfone UF hollow fiber membranes using amphiphilic Pluronic block copolymers as poreforming additives. J Memb Sci 2011; 380(1-2): 114-23. doi: 10.1016/j.memsci.2011.06.041.

24. Safari NHM, Hassan AR, Che Wan Takwa CWI, Rozali S. Deduction of surfactants effect on performance, morphology, thermal and molecular properties of polymeric polyvinylidene fluoride (PVDF) based ultrafiltration membrane. Period Polytech Chem Eng 2019; 63(1): 27-35. doi: 10.3311/PPch.12423.

25. Amirilargani M, Saljoughi E, Mohammadi T. Effects of Tween 80 concentration as a surfactant additive on morphology and permeability of flat sheet polyethersulfone (PES) membranes. Desalination 2009; 249(2): 837-42. doi: 10.1016/j.desal.2009.01.041.
26. Amirilargani M, Saljoughi E, Mohammadi T. Improvement of permeation performance of polyethersulfone (PES) ultrafiltration membranes via addition of Tween-20. J Appl Polym Sci 2010; 115(1): 504-13. doi: 10.1002/app.30814.

27. Nasrul A, Bastian A, Sri M, Yoshikage O, Hideto M. Improved fouling reduction of PES hollow fiber membranes by incorporation with non-ionic surfactant. Res J Che Environ 2011; 15(2): 212-6.

28. Arahman N, Maruyama T, Sotani T, Matsuyama H. Fouling reduction of a poly(ether sulfone) hollow-fiber membrane with a hydrophilic surfactant prepared via non-solventinduced phase separation. J Appl Polym Sci 2009; 111(3): 1653-8. doi: 10.1002/app.29149.

29. Omidvar M, Soltanieh M, Mousavi SM, Saljoughi E, Moarefian A, Saffaran H. Preparation of hydrophilic nanofiltration membranes for removal of pharmaceuticals from water. J Environ Health Sci Eng 2015; 13: 42. doi: 10.1186/s40201-015-0201-3.

30. Myers D. Surfactant Science and Technology. 3rd ed. USA:Wiley; 2005. p.107-59. doi: 10.1002/047174607X.ch4.

31. Kakihana Y, Cheng L, Fang LF, Wang SY, Jeon S, Saeki D, et al. Preparation of positively charged PVDF membranes with improved antibacterial activity by blending modification: effect of change in membrane surface material properties. Colloids Surf A Physicochem Eng Asp 2017; 533: 133-9. doi: 10.1016/j.colsurfa.2017.08.039.

32. Datta S, Mahapatra N, Halder M. pH-insensitive electrostatic interaction of carmoisine with two serum proteins: a possible caution on its uses in food and pharmaceutical industry. J Photochem Photobiol B 2013; 124: 50-62. doi: 10.1016/j.jphotobiol.2013.04.004.

33. Nazar MF, Murtaza S, Ijaz B, Asfaq M, Mohsin MA. Photophysical investigations of carmoisine interacting with conventional cationic surfactants under different $\mathrm{pH}$ conditions. J Dispers Sci Technol 2015; 36(1): 18-27. doi: 10.1080/01932691.2014.884465.

34. Sadeghi A, Ehrampoush MH, Ghaneian MT, Najafpoor AA, Fallahzadeh $\mathrm{H}$, Bonyadi $\mathrm{Z}$. The effect of diazinon on the removal of carmoisine by Saccharomyces cerevisiae. Desalin Water Treat 2019; 137: 273-8. doi: 10.5004/dwt.2019.23189.

35. Tran TTV, Kumar SR, Lue SJ. Separation mechanisms of binary dye mixtures using a PVDF ultrafiltration membrane: donnan effect and intermolecular interaction. J Memb Sci 2019; 575: 38-49. doi: 10.1016/j.memsci.2018.12.070.

36. Zeng G, Ye Z, He Y, Yang X, Ma J, Shi H, et al. Application of dopamine-modified halloysite nanotubes/PVDF blend membranes for direct dyes removal from wastewater. Chem Eng J 2017; 323: 572-83. doi: 10.1016/j.cej.2017.04.131.

37. Mansourpanah Y, Alizadeh K, Madaeni SS, Rahimpour A, Soltani Afarani H. Using different surfactants for changing the properties of poly(piperazineamide) TFC nanofiltration membranes. Desalination 2011; 271(1-3): 169-77. doi: 10.1016/j.desal.2010.12.026.

38. Religa P, Kowalik-Klimczak A. Effect of interaction between anionic surfactants and poly(piperazine-amide) nanofiltration membranes used for chromium(III) recovery from saline solution. Water Sci Technol 2015; 72(10): 18039. doi: 10.2166/wst.2015.406. 